\title{
Colonialidade na dança e as formas africanizadas de escrita de si: perspectivas sul-sul através da técnica Germaine Acogny
}

Coloniality in dance and the Africanized forms of self-inscription: South- South perspectives thought Germaine Acogny's Technique

Luciane Silva ${ }^{1}$

Inaicyra Falcão dos Santos ${ }^{2}$

RESUMO

Situado no campo transversal entre educação, dança e antropologia, na esteira da reflexão sobre corpo e cultura, nosso texto busca apresentar as preocupações principais do campo da teoria social que investiga a colonialidade que ora utilizamos como mola propulsora para ampliar as perspectivas epistemológicas no campo de conhecimento da dança. No percurso investigativo apresentamos a técnica Acogny enquanto epistemologia do sul e possível conexão atlântica.

Palavras-chave: Colonialidade. Dança. Germaine Acogny.

\section{ABSTRACT}

Placed at the crossroads of education, dance and anthropology, addressing body and culture, the article presents key concerns in the field of social theory investigating coloniality as a driving force to broaden epistemological perspectives in the dance field. In the investigative course we present Acogny technique as an epistemology of the south and a possible atlantic connection.

Keywords: Coloniality. Dance. Germaine Acogny.
Doutoranda em Artes da Cena pela Universidade Estadual de Campinas. ORCID: http://orcid.org/ oooo-0002-1723-719X Contato: lucianeramoss@gmail.com 2. Profa. Dra. Livre docente colaboradora da Universidade Estadual de Campinas. ORCID: http://orcid.org/ 0000-0001-6321-6325 Contato:

inaicyra@gmail.com 
Sendo o corpo fluidez de memórias, superfície e continente de inscrições culturais e políticas, entidade viva capaz de perguntar e responder de diferentes maneiras a treinamentos, linguagens e estéticas, impõe-se ao nosso tempo o desafio de ampliar as paisagens epistemológicas que sugerem sentidos e sensos para os corpos que dançam.

Elaboramos a travessia deste texto pisando o campo transversal da dança, educação e antropologia enquanto áreas do conhecimento que produzem reflexões sobre a multiplicidade da sociedade brasileira nos seus trânsitos complexos entre estéticas hegemônicas e subalternizadas.

Constatando que a realidade de produção de conhecimento no Brasil está profundamente marcada pela colonialidade - aqui compreendida como a permanência de estados de presença fundados na ordem colonial nos séculos XIV nas Américas e XIX nas Áfricas, durante os processos de exploração territorial, econômica e política - buscamos adentrar o campo amplo e contrastante da teoria social que se dedica a discutir a imposição unilateral de epistemologias eurocêntricas. Pretendemos oferecer uma proposta reflexiva ao campo de conhecimento da dança, pouco poroso para a multiplicidade que pode habitar a educação do corpo e obtusa em relação à potência estética e poética presente nas formas africanizadas de escritas de $\mathrm{si}^{3}$, comumente subsumidas pela perspectiva do folclórico e do acessório excêntrico.

Tocar no tema da colonialidade impõe-nos a reflexão sobre como a diversidade de pensamentos tem sido acomodada nas esferas da educação em dança, especificamente nos cursos de graduação (bacharelado e licenciatura) e limitada por formas de saber que impedem a chegada de pedagogias alternativas aos modos dominantes. A assunção da multidimensão brasileira, pautada pelo substrato cultural negro e índio, faz emergir propostas elaboradas além e nas frestas dos cânones que monopolizaram por séculos as noções epistemológicas nas diversas áreas do conhecimento, impondo receitas homogêneas validadas como únicas formas de saber.

Ao defendermos a necessidade de pedagogias alternativas não nos referimos à seleção de disciplinas especiais ou "eventos temáticos", que frequentemente soam como paliativos frente à urgência de relações mais horizontais entre as propostas de formação oriundas dos contextos do norte hegemônico e aquelas originadas dos espaços subalternizados. Propomos que as diversas tradições e contemporaneidades pautadas pelas formas africanizadas de escritas de si sejam consideradas dentro do amplo território de conceitos e métodos legitimados pelo campo da pesquisa e formação em dança.
A ideia do termo "formas africanizadas de escritas de si" surge da leitura da obra "Formas africanas de auto inscrição" do filósofo camaronês Achille Mbembe, em que analisa criticamente os diversos essencialismos construídos em torno de determinadas leituras sobre a experiência africana, reforçando sobretudo o perigo da busca irrefletida de uma alteridade africana sem $o$ devido reconhecimento das especificidades culturais, políticas e geográficas no continente. Criticamos os essencialismos que nascem interna e externamente à experiência africana e consideramos a possibilidade de, ao utilizarmos a ideia de "africanização", assumirmos os substratos africanos que compõem a experiência brasileira. 


\section{Alicerces teóricos}

Valorizando a interdisciplinaridade como território fértil para a análise do corpo que dança e suas relações com a vida social, assim como a oportunidade de traçar diálogos críticos onde corpo e cultura sejam encarados com relevância, apresentaremos algumas propostas que servem para avaliarmos o eurocentrismo que acomete o campo do pensamento em dança. Abordamos alguns pressupostos norteadores focados na ideia de colonialidade, apresentando as linhas gerais de pensamentos que nos parecem úteis para re-localizarmos os saberes afro-orientados ${ }^{4}$ com a devida agência e refletirmos criticamente sobre o que intitulamos colonialidade do gesto - a presença de formas, percepções e concepções sobre corpo, movimento e seus contextos influenciados pelas lógicas coloniais - que por sua vez se vincula ao fato de que as linguagens, técnicas, métodos e treinamentos eleitos pelos espaços de formação universitária em dança são predominantemente fundamentados por conhecimentos produzidos no norte hegemônico.

Para discutir as bases da colonialidade retomamos brevemente a crítica ao colonialismo edificada por uma série de intelectuais que, em seus contextos e tempos específicos, discutiram os impactos da interferência europeia nas existências dos povos submetidos. Frantz Fanon (1925-1961), ensaísta, psiquiatra e militante envolvido nos processos de descolonização africana dedicou grande parte de sua produção intelectual ao campo do pensamento anticolonial apresentando perspectivas teóricas que serviram de base para muitas das elaborações que posteriormente discutiram os impactos do colonialismo. As obras "Os condenados da terra" (1979) e "Pele negra, máscaras brancas" (1963) foram basilares nas elaborações da chamada crítica pós-colonial. O primeiro, dando as bases fundamentais para o entendimento da relação colonizador/ colonizado e suas implicações, e o segundo historicizando e analisando de maneira contundente a experiência colonial na psicologia da pessoa negra. O legado de Fanon está relacionado, entre outros aspectos, com a sangria provocada pela engrenagem colonialista que fissurou não apenas a esfera social, mas os sentidos e identidades humanas. Suas ideias influenciaram muitos intelectuais do campo do pensamento pós-colonial, entre eles Homi Babha (1949-), Gayatri Chakravorty Spivak (1942 - ), Edward Said (1932-2014), Stuart Hall (1932 - 2014) e Paul Gilroy (1956 - $)^{5}$.

Nos estudos pós coloniais, uma ampla gama de temas até então pouco abordados tornaram-se foco através de propostas anunciadas por intelectuais provenientes de espaços colonizados. Representação, diferença, raça, migração e gênero passaram a
4.

Orientar o trajeto do pensamento crítico a partir das estéticas e poéticas do Atlântico Negro.
Autores como o literato nigeriano Chinua Achebe, o escritor queniano Ngugi wa Thiong'o, o filósofo congolês Valentin-Yves Mudimbe e o filósofo camaronês Achille Mbembe, também compõem o campo da crítica pós colonial. 
ser discutidos a partir da perspectiva das diversas comunidades subalternizadas e das teorias que emergiram desses espaços preocupadas em analisar o fato do colonialismo e suas consequências permanentes nas relações sociais. Não se trata de um campo com matriz teórica homogênea, mas traz preocupações comuns para a desconstrução dos essencialismos edificados pela modernidade e um programa teórico político que vislumbra a transformação social e o enfrentamento da opressão. O que esses autores desenvolveram, a partir de seus lugares de enunciação teórica (são intelectuais oriundos/as sobretudo da diáspora negra ou migratória), é a crítica às matrizes de conhecimento que, por se legitimarem em contextos europeus, reproduzem as lógicas e relações coloniais. Há grande diversidade nas gerações que produziram as teorias pós-coloniais, dos anos 1970 até nossos dias, bem como diversas críticas às suas capacidades de extrapolarem a teoria e anunciarem a práxis. Assim, o pós-colonial não denota necessariamente a ideia de uma superação do colonialismo, mas a discussão crítica para compreender suas bases e permanências.

\section{Colonialidade e pensamento latino-americano}

No início dos anos 2000 surge um grupo de intelectuais provenientes de diversos países da América Latina que propõem leituras acerca do colonialismo mirando a crítica ao sistema colonial enquanto entidade presente, trazendo de maneira mais pontual e conceitual a ideia de colonialidade em contraposição com colonialismo. Trata-se de um grupo heterogêneo, que não se apresenta enquanto "escola de pensamento", mas compartilha a crítica às epistemologias eurocentradas e suas engrenagens de poder. $\mathrm{O}$ sociólogo peruano Aníbal Quijano, o semiótico argentino Walter Mignolo, os sociólogos porto-riquenhos Ramón Grosfoguel e Nelson Maldonado-Torres e a pedagoga equatoriana Catherine Walsh são alguns desses autores.

O debate que edificam busca anunciar categorias de análise que enfrentem criticamente as realidades específicas latino-americanas no complexo modernidade/colonialidade, apontando como proposta a decolonialidade, entendida como a crítica ativa às heranças coloniais a partir das sabedorias oriundas das culturas latino-americanas.

Contemporânea a esse grupo é a socióloga, historiadora e ativista boliviana Silvia Cusicanqui Rivera, que, embora não coadune com o conceito de colonialidade ${ }^{6}$, fomenta teorias gestadas a partir das perspectivas dos povos de cultura Aimara aimara ${ }^{7}$, propondo construções epistemológicas a partir dos gestos, linguagens,
6.

A autora compreende que o colonialismo é uma estrutura internalizada e que permanece como uma realidade imanente, um processo ativo que se reproduz em todas as instâncias sociais.

7.

População que desde a era pré colombiana habita as regiões dos atuais territórios da Bolívia, Peru e Chile. 
simbologias e signos dessa cultura. Para a autora, é necessário resgatar o senso de totalidade que a modernidade e o capitalismo desarticularam através do corte cartesiano entre corpo/mente, alma/pensamento, que solidificaram dicotomias absorvidas pelo imaginário coletivo.

A leitura desses projetos teóricos nos coloca a pergunta: como incorporar essas questões em projetos que ultrapassem o meramente analítico e discursivo? O sociólogo português Boaventura de Sousa Santos traz a ideia de epistemologias do sul - procedimentos de criação e validação do conhecimento a partir da perspectiva daqueles que sofreram sistematicamente as destruições e exclusões causadas pelo colonialismo, capitalismo e sexismo. Para o autor, é necessário empreender o que chama de sociologia das ausências: tornar visível o que foi produzido como invisível ou como não existências. Sua proposta, intitulada ecologia de saberes, se fundamenta numa relação orgânica entre os saberes do sul ${ }^{8} \mathrm{e}$ torna-se mais uma possibilidade de leitura crítica que traz paradigmas para a emancipação social.

Essa perspectiva de ampliação simbólica dos pensamentos que emergem do sul é um princípio crucial para a desconstrução positiva dos espaços de produção de conhecimento que ora propomos. Levantamos, portanto, a reflexão sobre como as teorias propostas pelos contextos do norte, basilares nas estruturas oficiais de produção de saber no chamado sul global, podem ser repensadas à luz de nossos próprios contextos e realidades. A ponderação sobre a colonialidade nos provoca a anunciar intelectuais, histórias, linguagens e saberes até então mantidos nas periferias da produção de conhecimento.

No pensamento brasileiro, referenciamos intelectuais do campo da cultura e educação tais quais Santos (1996), Sodré (2005), Nóbrega (1991), Martins (1997), Moura (1988) e Nascimento $(1989)^{9}$, que abordando os pensamentos oriundos dos contextos afro-orientados desenharam conceitos e práticas pedagógicas. Tais referências fortalecem nossa posição intelectual e nos permitem compreender que esse esforço critico à colonialidade a partir de experiências negras é vívido em contextos brasileiros de produção de conhecimento não hegemônico.

Consideramos que descolonizar não é uma reivindicação ingênua de abandono de epistemologias canônicas, mas sim um exercício gradativo de reinvenção e revisão crítica quebrando as insularidades dos espaços produtores de saber. Quais são as bases teóricas de nossa produção de saberes? Por onde circulam nossas teorias, quais são nossas referências? Que diálogos empreendemos com o continente africano para além do estereótipo da ajuda huma-
8.

A noção de sul está muito além do geográfico e inclui os contextos subalternizados do norte.

9.

Entre as obras desses autores consideramos relevantes para nossa abordagem: Inaicyra Falcão dos Santos discute as contribuições afrIcano-brasileiras no campo da prática pedagógica Corpo e ancestralidade; O sociólogo Muniz Sodré, destrincha os aspectos estéticos que fundamentam as culturas negras, sobretudo as de matriz sudanesa, nas obras O terreiro e a cidade e A verdade seduzida; A coreógrafa e pedagoga Nadir Nóbrega aborda as contribuições do coreógrafo Clyde Morgan, cujo pensamento de dança mostra-se atravessado por contextos africanos afro-diaspóricos, na constituição da dança produzida em contextos soteropolitanos; A ensaísta e dramaturga Leda Maria Martins, em sua obra, Afrografias da memória, propõe o conceito de encruzilhada como lócus tangencial de simbolismos da experiências negra. 
nitária? Parece importante reavaliar o campo dos estudos em dança e introduzir reflexões aprofundadas sobre os contextos que fundamentam nossos saberes corporais. E não se trata de reivindicar certo "direito à fala", mas ampliar, com o devido tônus, as perspectivas em relação ao que vêm a ser as epistemologias no campo da dança e abordar suas pluralidades, mirando com todo o corpo as diversas propostas oriundas de contextos ainda pouco visitados.

\section{Mirando o Atlântico - travessias com Germaine Acogny}

Compreendendo a relação com a memória africana enquanto possibilidade de atualizar os fios que unem o Brasil e as Áfricas, bem como estabelecendo conexões sul-sul viáveis para o século XXI, partilhamos alguns sentidos resultantes do encontro com a técnica Germaine Acogny.

A coreógrafa, pedagoga e bailarina nasceu em Porto Novo, Benin, em 1944 e ainda criança, mudou-se para o Senegal, país da África do Oeste. Sua trajetória na confluência das africanidades com as linguagens de dança clássica e moderna na edificação de uma proposta técnica sistematizada nos anos 1980, resultou em uma proposta intercultural no campo da pedagogia de dança.

Após formar-se em educação física e ginástica rítmica na França, Germaine atua como chefe de departamento do Instituto Nacional de Artes de Dakar, onde introduz o que denominou dança negro- $a-$ fricana no programa de formação da instituição. Depois de longa jornada no campo do ensino, bem como atuando como intérprete, a artista é convidada a assumir a posição de diretora artística do Centro Africano de Pesquisa e de aperfeiçoamento do Intérprete, - Mudra Afrique ${ }^{10}$, projeto fomentado pelo então presidente Leopold Sedar Senghor, que convidou o coreógrafo belga Maurice Béjart para a direção geral do pioneiro empreendimento.

Eram tempos de transformação em diversos contextos do continente africano e, em muitos deles nascia um pensamento novo sobre o significado e amplitude das culturas africanas. O então primeiro presidente eleito após a derrubada do colonialismo francês propôs uma política de Estado que privilegiava a arte enquanto instância fundamental do desenvolvimento nacional. Esse pensamento perpassou de maneira semelhante muitos governantes de outras nações africanas, na criação de trupes e balés nacionais ${ }^{11}$, numa evidente assunção do patrimônio nacional.

Assim, a criação do Mudra consolidava-se como mais uma ação da política Senghoriana de inserção das artes enquanto parte privilegiada dos planos de política cultural e no empreendimento de uma ideia de unidade política atrelada à consciência das
10.

Mudra, que em sânscrito significa gesto, é uma escola de dança fundada em Bruxelas em 1970 por Maurice Béjart. Financiada pela Unesco, a escola tinha dimensão internacional com um quadro de artistas oriundo de diversas partes do mundo. o Mudra Afrique seria uma espécie de filial africana.

11.

Um breve mapeamento sobre os balés nacionais é apresentado em Silva (2012). 
identidades culturais das civilizações negras, fazendo da arte e da cultura prioridades nacionais ${ }^{12}$. Em uma perspectiva mais ampla relacionada aos processos de independência africana, tratava-se da participação da dança nos processos de modernização dos jovens Estados africanos.

Mudra Afrique - contornos do gesto

Para o Mudra Afrique foram recrutados bailarinos de diversos países do continente africano visando a uma formação de três anos que previa a aprendizagem ancorada nas tradições africanas em relação com linguagens das estéticas modernas europeias. Ensinava-se danças da África do Oeste, dança clássica, moderna (técnica Graham), ritmo, canto e teatro, dentro de uma perspectiva na qual o bailarino era encorajado a se situar de maneira profunda nas artes do espetáculo ${ }^{13}$.

O desejo da existência de um "novo balé negro-africano" que "participasse do universal" foi o grande mote do empreendimento, a partir de uma ideia de assimilação conceitualmente delineada por Senghor e praticada por Béjart na articulação do balé clássico com as linguagens africanas. A ideia de "se enraizar nos valores da negritude para se abrir aos valores de outras culturas", tal qual afirmava Béjart, foi levada a cabo através da atuação de Germaine Acogny, que tinha, entre outras missões, a tarefa de inventariar as danças patrimoniais locais e comunicá-las com as danças europeias.

A comunicação entre as estéticas europeias e africanas propostas nas diretrizes do Mudra sob a regência de Béjart foi movida por muitas ambiguidades, sobretudo a partir da proposta hierarquizada que pautava a relação entre as danças africanas e europeias, reproduzindo nas entrelinhas um discurso ambivalente que, embora afirmasse o caráter fundante da dança nas expressões dos povos africanos, resvalava na desgastada percepção do corpo inato, onde as diferenças físicas seriam herdadas geneticamente, reforçando a ideia de que esses povos dançavam "naturalmente". Ao reconhecer a expressividade vivaz própria dos africanos supunha-se também a superioridade da racionalidade europeia, capaz de "ordenar" as potências africanas.

A presença de Germaine Acogny enquanto mulher senegalesa, ciente das questões locais, além de sua perspicácia e sagacidade, contrabalancearia o eurocentrismo béjartiano, sem que se distanciasse dos ideais chave propulsores do desenvolvimento almejado por Senghor. No processo de direção artística da escola, a coreógrafa elaborou seu livro, Danse Africaine, que almejava
12.

Tal pensamento foi atravessado por uma série de contradições e críticas que envolviam a filiação de Senghor ao establishment francê bem como seus pensamentos essencializados sobre as identidades.

13.

Depoimentos de Germaine Acogny e Irene Tassembedo, ex-participante do Mudra, estão disponíveis no documentário A dançarina de Ébano (BORO, 2002). 
sistematizar o conteúdo das danças negras trabalhadas na escola e que desconstruía o imaginário comum de que as danças africanas estariam sustentadas por perspectivas simplórias e limitadas, herança do ideário colonial que criou polaridades tais quais selvagens/civilizados, sociedades/tribos, racional/emocional.

Em seu livro, publicado em inglês, francês e alemão, com três edições alcançadas, Acogny formaliza um repertório de movimentos base e construindo um sistema organizado.

O percurso do Mudra Afrique se estende de 1977 a 1982 e é enfraquecido por falta de recursos. Acogny se expatria na Europa, onde permanece por cerca de vinte anos. Seu retorno ao país natal acontece nos anos 1990, quando organiza workshops para estrangeiros em Casamance, no Sul do Senegal, e posteriormente em Toubab Djalaw, quando funda em 1998 a Ecole des Sables - Centro internacional de danças tradicionais e contemporâneas africanas - criado com o objetivo de proporcionar o desenvolvimento do campo da dança no continente africano com um viés de formação e profissionalização. Seu projeto pedagógico, estrutura arquitetônica e programa de cursos a coloca como importante referência para a formação e aperfeiçoamento de artistas da dança de diferentes continentes.

A técnica - gesto e sensibilidade

A técnica Acogny é uma filosofia, uma maneira de viver, de ver a vida. Germaine Acogny

Germaine Acogny produz um pensamento consolidado em dança a partir da síntese entre danças do Oeste Africano, sobretudo das regiões do Senegal e Benin, associadas à dança clássica e à dança moderna. O elemento condutor dessa relação entre culturas é a ligação expressa com as forças da natureza e com uma percepção do universo enquanto energia integrada ao corpo. Essa noção de um corpo considerado globalmente e cuja energia circula em si e no universo é premissa presente em diversas culturas africanas. Trata-se da percepção fundamental do corpo como cosmos e como mobilizador de energias vitais de maneira muito concreta.

Esse diálogo que, segundo Germaine, é filosofia da vida e do corpo, constitui-se também em uma percepção da espiritualidade, algo distinto de qualquer filiação religiosa, tal qual costuma-se referir quando aborda-se as artes africanas. Trata-se de uma conexão da pessoa que dança com os contextos ao redor, numa perspectiva somática, em oposição ao entendimento no registro 
"europeu orientalista", onde as práticas corporais de Ásia e África são consideradas esotéricas. Assim, o conceito de corpo-cosmos vai muito além de um saber holístico, mas é base para que a pessoa que dança se empodere e tenha autonomia para gerir seu corpo e as escolhas que fará para alimentá-lo tecnicamente.

A técnica Acogny está profundamente relacionada com o imaginário e com a capacidade de dar concretude aos símbolos. Nela, os espaços do corpo recebem nomes específicos, entre os quais citamos: a área do osso esterno, na parte anterior do tórax, é denominada le soleil (o sol), não por acaso situa-se ali o plexo solar, espaço de fluxos energéticos entre a parte inferior e superior do corpo; a região ao redor da púbis, no baixo ventre é denominada les etoiles (estrelas); a sétima vértebra na região dorsal é denominada vértebra do prazer; o centro motor na região do ventre é chamado de jumba, literalmente "umbigo" na língua wolof.

Na sistematização da técnica, a coreógrafa não usa o termo "passo", mas sim, "movimento", que corresponde a uma série de informações motoras, sensoriais e simbólicas. Aprendemos o movimento do baobá, da palmeira da costa, da estrela do mar, do fromager, da boneca ashanti, do condutor, do tigre bravo, entre outros. Tal mobilização propõe uma relação e entendimento do movimento que extrapola a pesquisa de movimento dedicada apenas à articulação cineseológica e oferece o entendimento do movimento a partir do imaginário, suplantando a perspectiva meramente, pois é orientada a visualizar e sentir em si o símbolo.

Uma percepção arejada sobre a relação entre as linguagens afro-orientadas e euro-orientadas, somada à consciência da força criativa presente nas expressões tradicionais garantem um corpo firme para a proposta da técnica Acogny. Nela, a dança abriga qualidades e paisagens, assim, mais do que a forma por si, privilegia-se a esthesis. Preocupa-se com a eficiência do gesto mas, sobretudo, com o sentir da dança a partir da perspectiva subjetiva, valorizando as camadas de história da pessoa que dança e a experiência comunitária que conforma e dignifica o ser, rompendo o individualismo e abstração que caracteriza em grande medida o pensamento ocidental eurocêntrico e trazendo à baila prioritariamente um bem estar e satisfação, fruto do equilíbrio com o mundo.

Essa proposta que privilegia a sensação e o imaginário leva a pessoa a acessar estados que a dança, se compreendida apenas como forma, não é capaz de oferecer. Imaginar-se como uma árvore fromager, por exemplo, em sua grandeza, implica em manter os pés profundamente enraizados, se relacionando com o centro de gravidade e ao mesmo tempo sentindo como se extremidades corporais tivessem galhos, se relacionando com a exterioridade 
ampla do mundo e buscando a ampliação do gesto. Nele há um engajamento da coluna e dos rotadores da área coxofemoral em uma ondulação contínua e minimalista, num trabalho interior de percepção do movimento, tal qual uma árvore antiga, que se move marcada por uma noção de tempo que não é necessariamente sinônimo de velhice, mas de experiência. Manter essa relação equilibrada, expandindo os espaços internos e crescendo ao infinito é um grande desafio, não apenas para a manutenção do equilíbrio físico, como também em nosso dilema cotidiano em lidar com as questões que nos atravessam enquanto pessoas no mundo.

No conteúdo da técnica, o trabalho focado na coluna vertebral, que Acogny denomina serpente da vida, tem grande importância. As unidades dos membros, interpretando as partes do corpo como elementos do cosmos, a ordem postural desenvolvida na etapa da aula denominada de la marche, onde trabalha com elementos ligados à coordenação motora, a coluna articulada, os pés profundamente ancorados na terra e a preocupação com o fluxo de energia agregam à técnica componentes de harmonia que Acogny resume na noção de corpo elegante - ótima e provocadora síntese, já que raramente o senso comum, colonizado e racista, oferece esse tipo de adjetivos às sabedorias negras.

A grande potência da técnica Acogny é sua expressa direção para a universalidade pluralista. Tomando perspectivas clássicas e contemporâneas ocidentais em relação com os classicismos, tradições e contemporaneidades africanas, cria-se um diálogo que coloca qualquer corpo em estado de presença. E não se trata de magia. Trata-se de uma técnica moderna em diálogo atual com a contemporaneidade, uma proposta que se estrutura em valores e percepções da tradição de maneira multidimensional. Quem entre os anos 1970 e 1980 proporia uma ideia de relação intercultural em um campo ainda tão restrito como o da sistematização técnica em dança no continente africano? Diante dos desígnios do colonialismo, é relevante que essa proposta tenha se protagonizado no sul subalternizado e que seja um conhecimento produzido por uma mulher africana. Nesse aspecto, parece justo chamar Acogny de "mãe da dança moderna africana", para além de jargões. E quando situamos e reforçamos tempo, espaço e contexto histórico, insistimos em assinalar que a coreógrafa insere os saberes africanos na modernidade, a mesma modernidade que excluiu e alienou o protagonismo negro. Esse pioneirismo é digno de nota para a história mundial da dança convencionada como abrangente e múltipla. Quiçá em breve sua biografia possa estar nos componentes curriculares de nossos cursos de graduação em dança enquanto referência da multiplicidade que constitui as produções 
de conhecimento sobre dança no mundo. Quiçá também, depois de conhecermos mais desses outros sul, possamos frequentar e dialogar com ele, redesenhando os cânones e dando outros tons para a história.

É tempo de reinventar os modelos que historicamente educaram nossos corpos, assentando-nos em diferentes pressupostos teóricos e práticos, ampliando criticamente as referências e as maneiras como nos percebemos desde dentro gerando corpos cientes de si e dos contextos ao redor. 


\section{REFERENNCIAS}

Acogny, Germaine. Danse africaine. Weingarten Kunstverlag, 1994, 4a. Ed. ISBN 10: 3881840389 ISBN 13: 9783881840385

BORO. Seydou. La Danseuse D' Ebène (França 2002). Documentário em cores/52'.

FANON, Frantz. Os condenados da terra. São Paulo, Civilização Brasileira, 1979.

MOURA, Clovis. Sociologia do negro brasileiro. São Paulo, 1988, Editora Ática.

NOBREGA, NADIR. AGO ALAFIJU, ODARA! A presença de Clyde Wesley Morgan na Escola de Dança da UFBA, de 1971 a 1978. Dissertação de mestrado PPGAC/UFBA. Salvador, 2006.

SANTOS, Boaventura de Sousa. Para uma sociologia das ausências e uma sociologia das emergência. In: SANTOS, Boaventura de Sousa (org). Conhecimento prudente para uma vida decente: um discurso sobre as ciências revisitado. São Paulo, Cortez, 2004.

SILVA, Luciane da. Conacry em movimento. História social, horoya e arte na África do Oeste. O Menelick2Ato, São Paulo, n.9, 2012. Disponível em: http://omenelick2ato.com/danca/conacry em-movimento/ 